Human and Animal Health

Vol.60: e17160317, January-December 2017

http://dx.doi.org/10.1590/1678-4324-2016160317 ISSN 1678-4324 Online Edition

AN INTERNATIONAL JOURNAL

\title{
Paper-Based Microfluidics Immunoassay for Detection of Canine Distemper Virus
}

\author{
Thiago Mazzu-Nascimento ${ }^{1,2}$, Fabiana Cristina Donofrio ${ }^{3}$, Beatriz Cutilak Bianchi ${ }^{4}$, \\ Regiane de Fátima Travensolo ${ }^{4}$, João Batista Souza Junior ${ }^{1}$, Daniel Angeli Moraes ${ }^{1}$, \\ Giorgio Gianini Morbioli ${ }^{1,2,5}$, Thiago Pinotti Segato ${ }^{4}$, Laudemir Carlos Varanda ${ }^{1}$, Emanuel \\ Carrilho $^{1,2^{*}}$. \\ 1 Instituto de Química de São Carlos, Universidade de São Paulo. 13566-590 São Carlos, SP, Brazil. ${ }^{2}$ Instituto \\ Nacional de Ciência e Tecnologia de Bioanalítica. Campinas, SP, Brazil. ${ }^{3}$ Universidade Federal de Mato Grosso, \\ Instituto de Ciências da Saúde. 78557267, Sinop, MT , Brazil. ${ }^{4}$ Partecurae Pesquisa e Desenvolvimento. 13560-460 \\ São Carlos, SP, Brazil. ${ }^{5}$ School of Chemistry and Biochemistry, Georgia Institute of Technology, Atlanta, Georgia \\ 30332, USA.
}

\begin{abstract}
Paper-based devices present low-cost and are versatile, making them very attractive for clinical analysis. To manufacture those devices wax patterns are printed on paper surface and upon heating the wax permeates through the entire thickness of the paper, creating hydrophobic barriers that delimit test areas. Antibodies produced in rabbits against canine distemper virus (CDV) were physically adsorbed on the surface of gold nanoparticles (AuNPs) and incubated with CDV viral antigens, forming the immunocomplex. Anti-CDV antibodies were immobilized into the microchannels by physical adsorption, forming the test region. The test solution containing conjugated AuNPs was applied at the bottom of the microchannel and it was eluted with a phosphate buffer solution $0.01 \mathrm{M} \mathrm{pH}$ 7.4. When the solution containing the AuNPs reached the test zone the recognition of antigens contained on the immunocomplex occurred with the consequent development of a red line, which represents a positive outcome for the test. This method demonstrated the success of physical immobilization of antibodies on AuNPs and the physical immobilization of antibodies on cellulose's surface. This colorimetric assay brings simplicity and versatility to clinical analyses, presenting potential for CDV diagnosis.
\end{abstract}

Key words: paper-based devices; wax printing; point-of-care testing; gold nanoparticles; canine distemper virus.

\footnotetext{
*Author for correspondence: emanuel@iqsc.usp.br
} 


\section{INTRODUCTION}

Paper-based microdevices provide low-cost, fast and portable analysis, being suitable for application in clinical analysis in needy regions ${ }^{1,2}$. Results from paperbased tests can be obtained on-site, on qualitative and semi-quantitative basis, or digitalized and send to an analysis center, for quantitative analysis by digital means ${ }^{3}$. The use of wax printing is an inexpensive and practical method for manufacturing microfluidic paper devices and requires only a wax printer and a hot plate or a lab oven. The printer deposits the wax onto the surface of the paper, and the hot plate melts the wax, which permeates through the entire thickness of the paper. This process creates hydrophobic barriers and produce channels suitable for individualized chemical reactions ${ }^{4}$.

Gold nanoparticles (AuNPs) have been extensively used in bioassays due to their optical properties and compatibility with biomolecules ${ }^{5}$. Colloidal solutions of AuNPs can exhibit different colorations, depending on their size, shape, and solvation, which is attributed to the surface plasmon resonance phenomena ${ }^{5}$. Several methods have been developed to optimize the production of AuNPs with controlled size and shape ${ }^{6}$ and surface ligands, to distinct applications ${ }^{7}$. AuNPs exhibit excellent affinity with various biomolecules, mostly through the interaction between those biomolecules with thiol and amino groups and the surface of AuNPs ${ }^{7}$, being one of the preferential attachment point ${ }^{8,9}$. Different organic molecules and biomolecules can be used to increase specificity of functionalized AuNPs bioassays with the target molecules, showing the versatility of the method ${ }^{10}$.

The Turkevich method is the most common chemical route to produce AuNPs and uses tetrachloroauric acid $\left(\mathrm{HAuCl}_{4}\right)$ and sodium citrate to reduce $\mathrm{Au}$ (III) cations to metallic $\mathrm{Au}$ in aqueous solution. Other synthetic methods use different reducing agents, distinct reducing condition (photochemical reduction) or different reactional conditions, such as $\mathrm{pH}$ and temperature ${ }^{11}$. The size of the nanoparticles can be tuned controlling the nucleation and growth of the nucleus formed at the beginning of the gold salt reduction by changing reaction temperature, reactional time and precursor concentration ${ }^{11}$.

The use of AuNPs in immunoassays is based mainly on the combination of nanoparticles with biomolecules of interest, such as DNA, antibodies, amino acids, small peptides, among others $7,12,13$, particularly antibodies, which enable the detection of specific antigens widely used in clinical diagnosis ${ }^{11,14}$. One strategy for the bioconjugation of gold nanoparticles is physical adsorption through electrostatic interactions, which allow interactions between surfaces with opposing charges. Under physiological conditions antibodies have an overall positive charge ${ }^{15}$, interacting electrostatically with the nanoparticles when in contact with them ${ }^{7}$. This method is common in laboratories as it is simple and efficient. Besides the fact that this is the easiest approach to immobilize antibodies onto the AuNPs surface, it results in a random distribution of antibodies, what can diminishes the binding affinity between the antibody and antigen, resulting in loss of sensitivity in bioassays 7. This inconvenience is minimized in qualitative and semi-quantitative readouts, such as in this low-cost bioassay, when in comparison with quantitative measurements.

Canine distemper virus (CDV) is an infectious disease caused by a virus, of the Morbillivirus genus, Paramyxoviridae family, that infects domestic dogs and carnivores ${ }^{16}$. The main symptoms are vomiting, diarrhea and respiratory affections, besides affecting the nervous system, leading the seizures, paraplegia, coma, and death ${ }^{16}$. Due to the fact that this disease presents a high mortality rate, its rapid diagnosis becomes extremely relevant. Among the most common diagnostic methods, the polymerase chain reaction (PCR) ${ }^{17}$ and the immunoassays ${ }^{18}$ are 
prominent, but immunochromatography assays arise as a new alternative for rapid diagnosis of $\mathrm{CDV}^{19}$. The functionalities of nanoparticles and the low cost of paperbased microdevices were combined to prospect a rapid and inexpensive test to CDV.

\section{MATERIALS AND METHODS}

\section{Paper microdevice production}

The platform was designed in the CorelDRAW software with a layout similar to that used in conventional lateral flow tests. The sheets of Whatman $\mathrm{N}^{\mathrm{o}} 1$ chromatographic paper were then cut to size A4 and inserted into the Xerox Phaser 8560 printer. Wax patterns were printed on the surface of the paper, creating the channels. Then, the printed microdevices were taken to a thermal press and heated for 2 min at a temperature of $150{ }^{\circ} \mathrm{C}$ to melt the wax on the surface and allow it to permeate to into the paper. The steps of manufacturing the paper microdevices are shown in Figure 1.

(a)

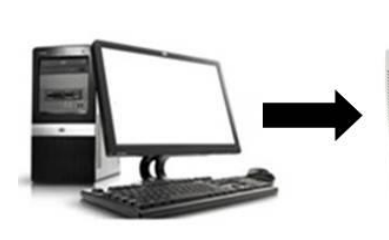

(b)

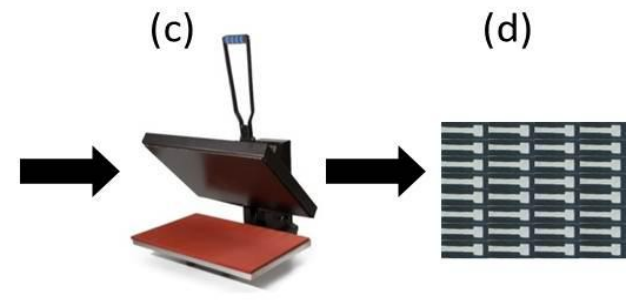

(e)

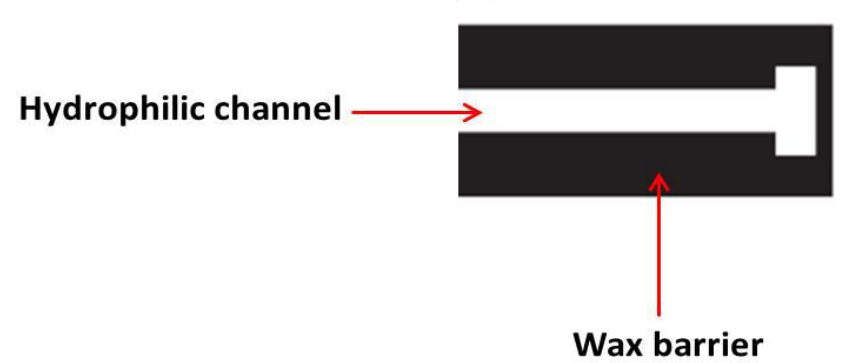

Figure 1. Steps involved in the production of the paper microdevices. (a) Designing layout. (b) Wax printing on the surface of the paper. (c) Heating wax printed paper with a heat press. (d) Several microdevices printed on a single sheet. (e) Example of a finished lateral flow microdevice.

Using the CorelDRAW software, microchannels of diameters ranging from 1 to 6 $\mathrm{mm}$ were designed in order to evaluate the most effective microchannel that lead to the smaller migration time.

\section{Gold nanoparticles (AuNPs) synthesis}

In order to synthesize particles with larger diameters and spherical shape two different methods were used: the Turkevich and the sodium borohydride methods.

\section{Turkevich method}

In a $250 \mathrm{~mL}$ round-bottom flask, $25.4 \mu \mathrm{mol}$ of $\mathrm{HAuCl}_{4} .3 \mathrm{H}_{2} \mathrm{O}$ were added to $95 \mathrm{~mL}$ of water, and this solution was heated to boiling point under stirring. Under these conditions, $5 \mathrm{~mL}$ of a sodium citrate solution $(1 \% \mathrm{~m} / \mathrm{m})$ was heated to $90{ }^{\circ} \mathrm{C}$ and quickly injected into the reaction medium. After $10 \mathrm{~min}$, this solution was cooled down to room temperature and the stirring was kept for another $15 \mathrm{~min}$. The colloidal solution was stored as-synthetized without further purification ${ }^{20}$. 
Martin method

An aqueous solution consisting of $\mathrm{HAuCl}_{4} \cdot 3 \mathrm{H}_{2} \mathrm{O}\left(50 \mathrm{mmol} \mathrm{L}{ }^{-1}\right)$ and $\mathrm{HCl}(50 \mathrm{mmol}$ $\left.\mathrm{L}^{-1}\right)$ was prepared. Another aqueous solution contained $\mathrm{NaOH}\left(50 \mathrm{mmol} \mathrm{L}^{-1}\right)$ and $\mathrm{NaBH}_{4}\left(50 \mathrm{mmol} \mathrm{L}^{-1}\right)$. For the synthesis of the AuNPs, $100 \mu \mathrm{L}$ of the $\mathrm{HAuCl}_{4} / \mathrm{HCl}$ solution were added to a test tube containing $9.6 \mathrm{~mL}$ of water at $25{ }^{\circ} \mathrm{C}$, under agitation using a vortex-type mixer. $300 \mu \mathrm{L}$ of the $\mathrm{NaBH}_{4} / \mathrm{NaOH}$ solution was quickly injected into the $\mathrm{HAuCl}_{4} / \mathrm{HCl}$ solution. The solution changed from light yellow to orange and then to red, indicating the formation of AuNPs, then the stirring was stopped after $1 \mathrm{~min}$ and the solution was stored in dark for further surface functionalization ${ }^{21}$.

\section{AuNPs Characterization}

Colloidal AuNPs solutions were characterized by UV-Vis spectroscopy using a JASCO V-630 series instrument. The presence of the surface plasmon resonance band (SPR) near $520 \mathrm{~nm}$ indicates nanoparticles formation. The concentration of particles was calculated by using the extinction coefficient from the literature ${ }^{8}$.

The morphology of the nanoparticles was analyzed at the Structural Characterization using a PHILIPS CM120 transmission electron microscope (TEM) operating at 120 $\mathrm{kV}$ and a JEOL JEM-2100 transmission electron microscope operating at $200 \mathrm{kV}$. The samples were prepared to analysis as follows: a small portion of the sample was dispersed in isopropanol, and $10 \mu \mathrm{L}$ of this dispersion was then dropped on a TEM copper grid containing a Formvar ${ }^{\circledR}$ film coated with a carbon sputtering. The solvent was allowed to evaporate slowly at room temperature, and the sample was kept in a vacuum for at least $24 \mathrm{~h}$. The diameter of approximately 150 nanoparticles was performed using ImageJ software to estimate the average particle diameter.

\section{Production of rabbit polyclonal antibodies against CDV and its partial purification}

The production of rabbit polyclonal antibodies against CDV (anti-CDV) was approved by Ethics Committee on Animal Use of Universidade Federal de São Carlos under No. 086/2012. Anti-CDV polyclonal was generated by immunizing rabbits with intradermal injections of $1.0 \mathrm{~mL}$ of viral suspension (respectively, 1.0 $\mathrm{mg} \mathrm{mL} \mathrm{L}^{-1}$ ) mixed with $1.0 \mathrm{~mL}$ Freund's complete adjuvant, in order of determine the concentration of viral suspension. Subsequent injections of viral suspension mixed with incomplete adjuvant were given weekly for a period of 4 weeks and then monthly for a period of 3 months. The rabbits were bled 7 days after the last dose. The immunoglobulin fractions of both sera were separated by precipitation with ammonium sulfate $\left(1.56 \mathrm{~mol} \mathrm{~L}^{-1} ; \mathrm{pH}\right.$ 6.5). Desalinization of the protein solution was performed using a dialysis sack (Sigma-Aldrich) with Molecular Weight Cut-Off (MWCO) of $12 \mathrm{kDa}$ against PBS buffer solution $\left(0.01 \mathrm{~mol} \mathrm{~L}^{-1}, \mathrm{pH} 7.4\right){ }^{22}$. Immunoglobulin fractions were stored at $-70{ }^{\circ} \mathrm{C}$ until use. This desalinization procedure by selective and passive diffusion through a semi-permeable membrane is common for protein purification, buffer exchange in protein solutions and also for sample preparation for ion exchange chromatography. Desalinization was used here to avoid gold nanoparticles aggregation during conjugation with anti-CDV.

\section{AuNP conjugation with anti-CDV antibodies}

Anti-CDV antibodies were physically adsorbed on the surface of gold nanoparticles (AuNPs). $1.5 \mathrm{~mL}$ of gold nanoparticles solution were adjusted to $\mathrm{pH} 9.0$ with 10 mmol L ${ }^{-1}$ borate buffer $\mathrm{pH} 9.2$. Then, under constant stirring, $100 \mu \mathrm{L}$ of the antibody solution $\left(100 \mu \mathrm{g} \mathrm{mL}^{-1}\right)$ were added and this solution was incubated under agitation for $20 \mathrm{~min}$ at $650 \mathrm{rpm}$. Then, $100 \mu \mathrm{L}$ of an aqueous bovine serum albumin (BSA) 
solution $\left(1 \mu \mathrm{g} \mathrm{mL}^{-1}\right)$ was added and the stirring was continued for another $20 \mathrm{~min}$ at $650 \mathrm{rpm}$. Finally, the solution was centrifuged at 14,000 rpm during $20 \mathrm{~min}$. The supernatant was removed and the conjugated AuNPs precipitate was resuspended in $300 \mu \mathrm{L}$ of a $2 \mathrm{mmol} \mathrm{L}^{-1}$ borate buffer (pH 7.4) ${ }^{23}$.

\section{Immunochromatographic trials}

The immobilization of anti-CDV antibodies in cellulose occurred by manual deposition onto the microchannel forming a line. This process used $5 \mu \mathrm{L}$ of antiCDV solution $\left(100 \mu \mathrm{g} \mathrm{mL}^{-1}\right)$ diluted at the ratio 1:4 in carbonate-bicarbonate buffer $\left(0.2 \mathrm{mmol} \mathrm{L}^{-1}, \mathrm{pH} 9.6\right)$, and the microplate containing the antibodies was maintained for $1 \mathrm{~h}$ at $37^{\circ} \mathrm{C}$ and overnight at $4{ }^{\circ} \mathrm{C}$.

As long as the purpose of this test was to identify the canine distemper virus antigens, $\mathrm{CDV}$ antigens $\left(635 \mu \mathrm{g} \mathrm{mL} \mathrm{m}^{-1}\right)$ were mixed at the ratio 1:2 with AuNPs conjugated with anti-CDV antibodies after sensitization. The immunocomplex was captured by the immobilized anti-CDV antibodies on the test line. Five microliters of the immunocomplex were applied at the bottom of the device, which were eluted with $200 \mu \mathrm{L}$ of PBS buffer solution $\left(0.01 \mathrm{~mol} \mathrm{~L}^{-1}, \mathrm{pH} 7.4\right)$ to permeate through the whole channel, being detected at the test line.

\section{RESULTS AND DISCUSSION}

\section{Nanoparticle synthesis}

The synthesis of gold nanoparticles is easily followed by eye. Initially, the $\mathrm{HAuCl}_{4} \cdot 3 \mathrm{H}_{2} \mathrm{O}$ solution presented a yellow color, but upon the formation of gold nanoparticles, the solution changed to a red color. Depending on the synthesis method AuNPs with different sizes are obtained. The Turkevich method ${ }^{20}$ generated spherical particles with an average diameter of $17.3 \mathrm{~nm}$ (Figures 2B, 2C, and 2D), while the Martin method $\left(\mathrm{NaBH}_{4}-\mathrm{NaOH}\right){ }^{21}$ generated smaller spherical particles, with an average diameter of $5.4 \mathrm{~nm}$ (Figures 2A, 2C, and 2D). Figure 2D shows the UV-Vis spectrum of Turkevich AuNPs and Martin AuNPs before and after antiCDV conjugation, showing that the conjugation process held colloidal stability for both methods. Since the conjugation of AuNPs with anti-CDV antibodies approach used in this work was based on unspecific electrostatic interactions 7, some parameters modulate the adsorption efficiency, such as: nanoparticles size, surface charge, $\mathrm{pH}$ and antibody concentration ${ }^{24}$. As IgG molecules are relatively large $(\sim 150 \mathrm{KDa})$, increasing the size of AuNPs also increases their total surface area, which could improve the adsorption ${ }^{25}$. Indeed, AuNPs synthesized via Turkevich method displayed bigger diameter than Martin nanoparticles and, in principle, has the ability to conjugate higher amount of IgG per particle. Therefore, antiCDV/AuNPs from Turkevich method were chosen to be used in the immunochromatographic assays. 

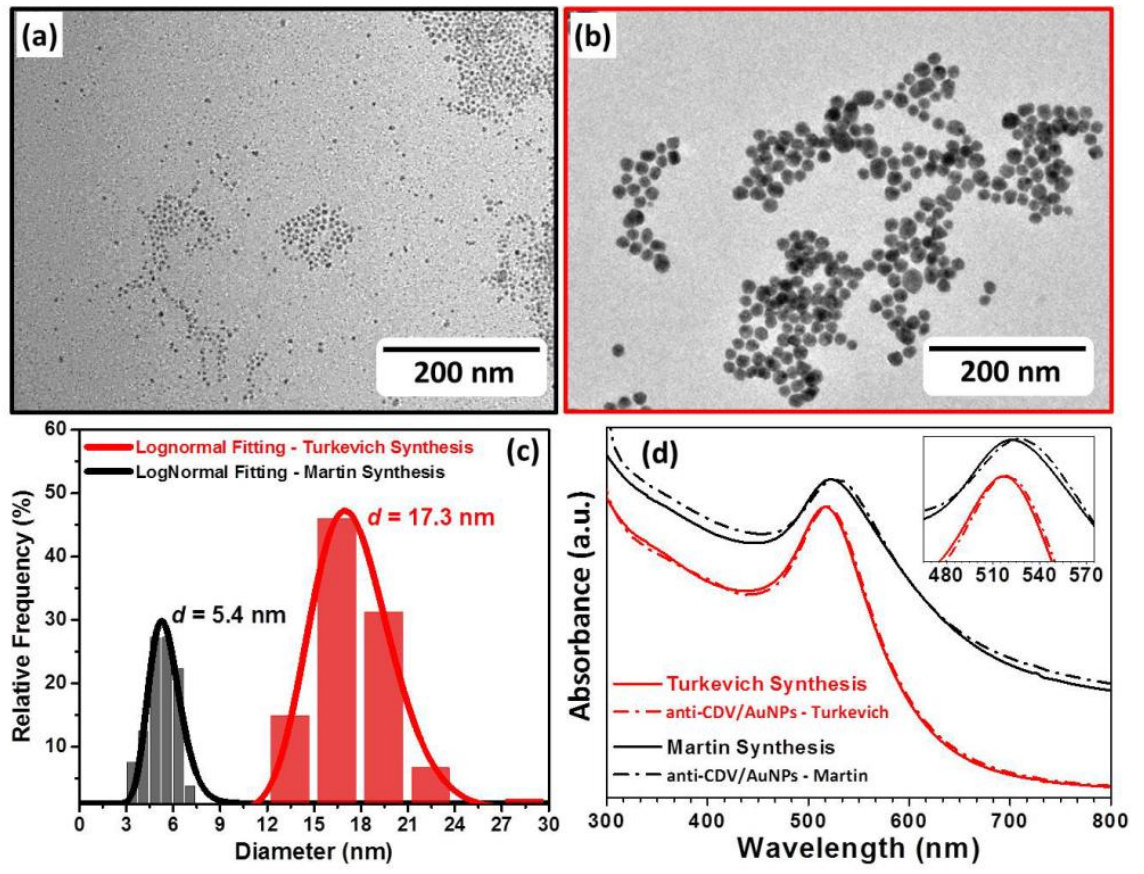

Figure 2. (a) TEM micrograph of AuNPs synthesized via Martin method; (b) TEM micrograph of AuNPs synthesized via Turkevich method; (c) Relative frequency counting and lognormal distribution fitting of both AuNPs samples showing their average diameter (d); (f) UV-Vis spectrum of both AuNPs suspension, Martin synthesis $\left(8 \times 10^{-8} \mathrm{~mol} \mathrm{~L}^{-1}\right)$ and Turkevich synthesis $\left(1.5 \times 10^{-9} \mathrm{~mol} \mathrm{~L}^{-1}\right)$ before and after anti-CDV conjugation.

\section{Microchannel optimization}

In order to evaluate the design of devices that allows the fastest migration rate of liquids into microchannel, six devices with the thicknesses of the hydrophilic channel ranging from 1 to $6 \mathrm{~mm}$ (nominal) were placed in contact with $200 \mu \mathrm{L}$ of red ink for pen (Waterman, Paris), to assess the migration time of the front of the solvent in each microchannel, as shown in Figure 3A to 3D. After melting, the wax spreads into the original area of channel, resulting in channels with smaller width than the nominal values originally printed ${ }^{4}$. 

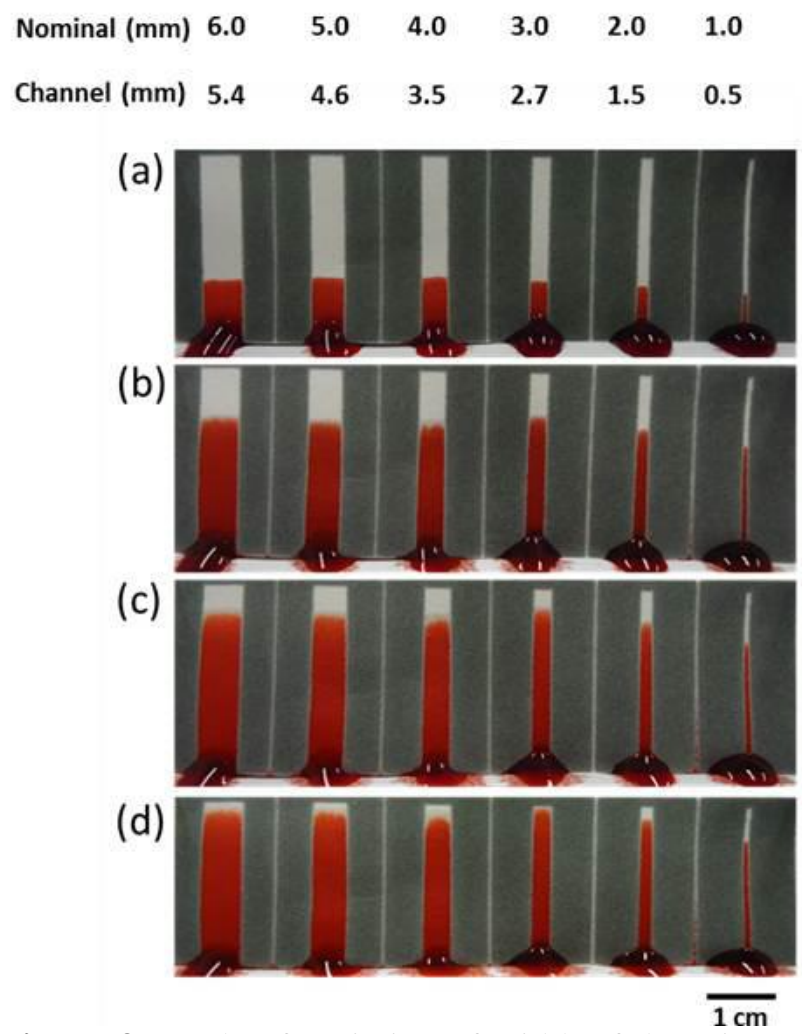

Figure 3. Study of variation of width of the microchannels and fluid migration times. (a) $30 \mathrm{~s}$ after the application of the test solution. (b) $1 \min 30 \mathrm{~s}$. (c) $2 \min 30 \mathrm{~s}$. (d) $3 \min 10 \mathrm{~s}$.

After 3:10 min, the channel filling was complete in the platform with $3 \mathrm{~mm}$ nominal diameter (2.7 $\mathrm{mm}$ channel), and thus this thickness was chosen to perform the lateral flow assay. When the printed microdevices are heated there is a narrowing of the channels due to the lateral spreading of the wax from the hydrophobic barriers, as described by Washburn Equation (Equation 1) ${ }^{26}$, characterized by the permeation of melted wax in the porous paper matrix due to capillary flow ${ }^{4}$. As long as the Washburn Equation is fluid and porous matrix dependent - the melted wax and the paper, respectively - there is a linear relationship between the width of the barrier and the printed line (Equation 2) and the width of the channel and the space between the hydrophobic barriers (Equation 3) ${ }^{4}$, what allows one to predict the final dimensions of the device during designing steps.

$$
\begin{aligned}
\mathrm{L} & =\left(\frac{\gamma \mathrm{Dt}}{4 \eta}\right)^{1 / 2} \\
\mathrm{~W}_{\mathrm{B}} & =\mathrm{W}_{\mathrm{P}}+2 \mathrm{~L} \\
\mathrm{~W}_{\mathrm{C}} & =\mathrm{W}_{\mathrm{G}}-2 \mathrm{~L}
\end{aligned}
$$

L: Distance percolated by the liquid

$\eta$ : Liquid viscosity

$\gamma$ : Surface tension

D: Pore diameter

t: Permeation time 
$\mathrm{W}_{\mathrm{B}}$ : Width of the barrier

$\mathrm{W}_{\mathrm{P}}$ : Width of the printed line

$\mathrm{W}_{\mathrm{C}}$ : Width of the hydrophilic channel

$\mathrm{W}_{\mathrm{G}}$ : Space between the two printed lines

\section{Immunochromatographic assays}

The simplest and fastest method of immobilization of biomolecules on cellulose support is through direct adsorption, in which the biomolecule of interest is noncovalently attached to the cellulose by intermolecular interactions such as hydrogen bonding, van der Waals, hydrophobic or electrostatic interactions ${ }^{27}$. However, depending on the complexity of the matrix in which the analytes are, the previously immobilized biomolecules can be removed from their original adsorption site what can affect later the detection step ${ }^{28}$. The immunocomplex solution (antibodies conjugated with AuNPs and complexed to viral antigens) applied to the paper was eluted with a larger volume of PBS buffer in order to avoid $\mathrm{pH}$ variations during the elution and thus preventing migration of the absorbed antibodies.

The immunocomplex solution presented a red coloration on paper that was almost completely absent when the diluent buffer was applied. Only when the fluid front containing the whole immunocomplex reached the previously immobilized antibodies on cellulose surface (the test and control lines, respectively), the antiCDV immobilized on paper recognized the antigen contained on the immunocomplex and interacted with it, thus forming the red line characteristic of a positive result. Non-specific interactions between the immobilized antibodies on cellulose surface and gold nanoparticles could result in a false positive outcome; however, such a problem is avoided by the recovering of the surface of the conjugated AuNPs with BSA, which blocks the surface of the nanoparticles from undesirable interactions ${ }^{29}$. If the antigen is absent in the original solution, then the immunocomplex will not interact with the previous immobilized antibodies on the surface of the cellulose and the AuNPs will not concentrate in that test/control region, and there will be no appreciable change in the color of paper to red, thus indicating a negative outcome. The Figure 4 schematizes all stages of a lateral flow assays. 
(a)

(b)

(c)

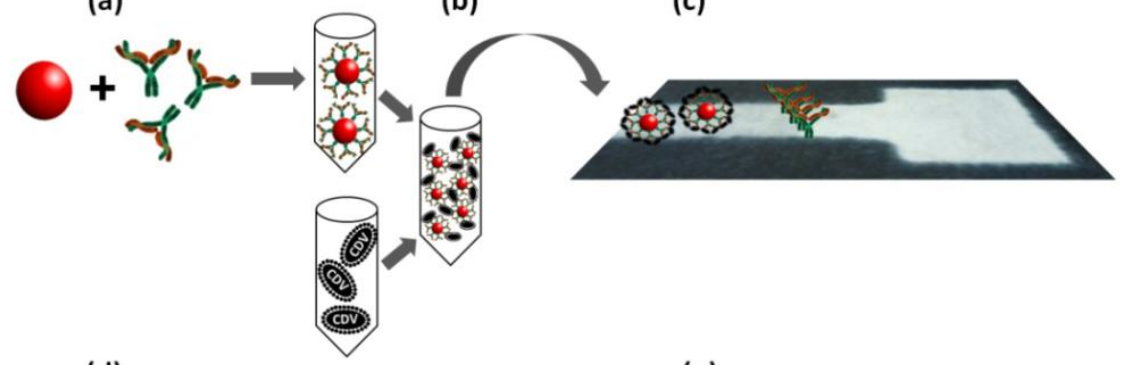

(e)
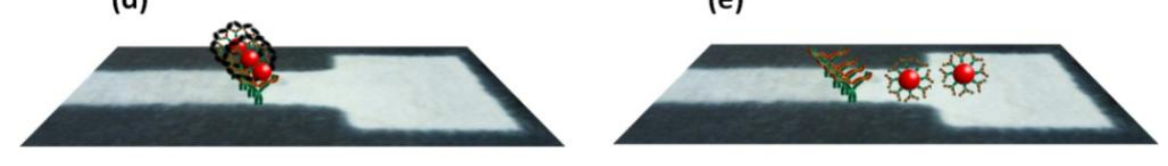

(f)

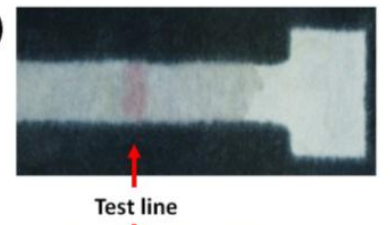

(g)
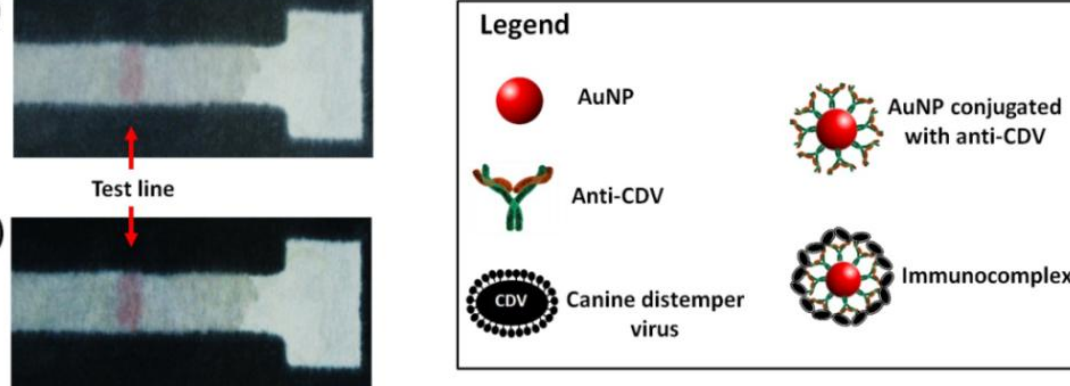

Figure 4. Lateral flow immunoassay on a single layer of paper. (a) Conjugation of gold nanoparticles with antiCDV. (b) Immunocomplex formation. (c) Anti-CDV antibodies immobilized on cellulose and application of immunocomplex solution at the bottom of microchannel. (d) Recognition of viral antigens contained in the immunocomplex by the immobilized anti-CDV. (e) Anti-CDV antibodies immobilized on cellulose surface and application of gold nanoparticles with antibodies solution (antigens are absent in this case) at the bottom of microchannel, not occurring recognition step between the anti-CDV immobilized with the antibodies in the nanoparticle, and thus there is no change in color in the test line (negative outcome). (f) Photograph of lateral flow positive assay. (e) Photograph of the lateral flow positive assay with an enhanced contrast (digital), for better visualization of the test line.

In the scheme presented in Figure 4 is possible to notice that after the immunocomplex application (Figure 4c) the solution reaches the immobilized antibodies zone on cellulose, and then the bio recognition occurs (Figure $4 \mathrm{~d}$ ) ${ }^{19}$, with the consequent development of a red line. The maintenance of the reddish color of the solution suggests the stability of the immunocomplex, corroborating with the spectra presented in Figure 2D. This line indicates that there was a recognition between canine distemper virus and antibodies from the AuNPs, what provides signal intensification and then the red color appears in the test line (Figure 4F; 4G). These results showed that the expected interaction between the immobilized antiCDV and the immunocomplex from the solution was efficient. Thus, we could monitor the success of the bioconjugation process with gold nanoparticles and the immobilization using bicarbonate/carbonate buffer. conjugation

The next step of this study involves method validation, in order to evaluate the ruggedness of devices, made by the comparison with standard methods (i.e., ELISA) 18. Furthermore, clinical trials should provide relevant information on the performance of test, such as sensitivity, specificity, and accuracy ${ }^{30,31}$. This new diagnostic tool focuses on the development of simple, cheap, and robust immunoassays, that would be used in a preliminary screening for the disease. 


\section{CONCLUSION}

Immunochromatographic assays using a single layer of chromatographic paper and wax printing arises as a prototype with potential clinical use due to their simplicity and low manufacturing costs. AuNPs synthesis by the Turkevich method resulted in gold nanoparticles with an average diameter of $17.4 \mathrm{~nm}$ and a spherical shape ideal for carrying out bioconjugations and for immunological applications. By varying the width of the microchannels we found out that channels with $2.7 \mathrm{~mm}$ presented the fastest wetting rates and were chosen as the preferential design for the microdevices. The simplest method of antibody bioconjugation with gold nanoparticles by physical adsorption made it possible to detect canine distemper virus at the test line, indicating the potential use of such devices at home or in veterinary clinics.

\section{ACKNOWLEDGEMENTS}

The authors would like to thank the funding agencies FAPESP (Grant N. 2011/13997-8 and 2012/02093-3), CNPq (Grants N. 311323/2011-1, N. 131306/2013-8 and 205453/2014-7) and CAPES for scholarships and financial support, ParteCurae Analysis for the rabbit polyclonal anti-CDV serum production, Biovet for the CDV virus strain, the Laboratory of the Department of Materials Engineering, Federal University of São Carlos and the Institute of Chemistry of São Carlos, University of São Paulo for using their facilities and equipment for AuNPs characterization.

\section{REFERENCES}

1- Carrilho E, Phillips ST, Vella SJ, Martinez AW, Whitesides GM. Paper microzone plates. Anal Chem. 2009;81:5990-8.

2- Martinez AW, Phillips ST, Whitesides GM, Carrilho E. Diagnostics for the developing world: microfluidic paper-based analytical devices. Anal Chem. 2010;82:3-10.

3- Martinez AW, Phillips ST, Carrilho E, Thomas SW, Sindi H, Whitesides GM. Simple telemedicine for developing regions: camera phones and paper-based microfluidic devices for real-time, off-site diagnosis. Anal Chem. 2008;80:3699-707.

4- Carrilho E, Martinez AW, Whitesides GM. Understanding wax printing: a simple micropatterning process for paper-based microfluidics. Anal Chem. 2009;81:7091-5.

5- Faraday M. The Bakerian Lecture: Experimental Relations of Gold (and Other Metals) to Light. Philos Trans R Soc London. 1857;147:145-181.

6- Nanodots S, Link S, El-sayed MA. Spectral Properties and Relaxation Dynamics of Surface Plasmon Electronic Oscillations in. J Phys Chem B 1999;103:8410-8426.

7- Fratila RM, Mitchell SG, Del Pino P, Grazu V, de la Fuente JM. Strategies for the biofunctionalization of gold and iron oxide nanoparticles. Langmuir. 2014;30:1505715071.

8- Elghanian R. Selective Colorimetric Detection of Polynucleotides Based on the DistanceDependent Optical Properties of Gold Nanoparticles. Science.1997; 277:1078-1081.

9- Mulvaney P. Surface Plasmon Spectroscopy of Nanosized Metal Particles. Langmuir 1996; 12:788-800.

10- Nath N, Chilkoti A. A colorimetric gold nanoparticle sensor to interrogate biomolecular interactions in real time on a surface. Anal Chem. 2002;74:504-9.

11- Panda B, Chattopadhyay A. Synthesis of au nanoparticles at "all" pH by $\mathrm{H} 2 \mathrm{O} 2$ reduction of HAuCl4. J Nanosci Nanotechnol. 2007;7:1911-5.

12- Ngo YH, Li D, Simon GP, Garnier G. Paper surfaces functionalized by nanoparticles. Adv Colloid Interface Sci. 2011;163:23-38.

13- Zhang C, Zhang Y, Wang S. Development of multianalyte flow-through and lateral-flow assays using gold particles and horseradish peroxidase as tracers for the rapid determination of carbaryl and endosulfan in agricultural products. J Agric Food Chem. 
2006;54:2502-7.

14- Linares EM, Kubota LT, Michaelis J, Thalhammer S. Enhancement of the detection limit for lateral flow immunoassays: evaluation and comparison of bioconjugates. J Immunol Methods. 2012;375:264-70.

15- Schoch A, Kettenberger H, Mundigl O, Winter G, Engert J, Heinrich J, et al. Charge-mediated influence of the antibody variable domain on FcRn-dependent pharmacokinetics. Proc Natl Acad Sci. 2015;112:5997-6002.

16- Carvalho OV, Botelho CV, Ferreira CGT, Scherer PO, Soares-Martins JAP, Almeida MR, Silva Júnior A. Immunopathogenic and Neurological Mechanisms of Canine Distemper Virus. Adv Virol 2012;1-10.

17- Fischer CDB, Ikuta N, Canal CW, Makiejczuk A, Allgayer MDC, Cardoso CH, Lehmann FK, Fonseca AS, Lunge VR. Detection and differentiation of field and vaccine strains of canine distemper virus using reverse transcription followed by nested real time PCR (RT-nqPCR) and RFLP analysis. J Virol Methods. 2013;194:39-45.

18- Cho KH, Kim J, Yoo HA, Kim DH, Park SY, Song CS, et al. Use of hydrophilic extra-viral domain of canine distemper virus $\mathrm{H}$ protein for enzyme-linked immunosorbent assay development. J Vet Sci. 2014;15:503-9.

19- An DJ, Kim TY, Song DS, Kang BK, Park BK. An immunochromatography assay for rapid antemortem diagnosis of dogs suspected to have canine distemper. J Virol Methods 2008;147:244-9.

20- Turkevich J, Stevenson PC, Hiller J. A Study of the Nucleation and Growth Processes in the Synthesis of Colloidal Gold. Discuss Faraday Soc. 1951;11:55-75.

21- Martin MN, Basham JI, Chando P, Eah S-K. Charged gold nanoparticles in nonpolar solvents: 10-min synthesis and 2D self-assembly. Langmuir. 2010;26:7410-7.

22- Rajukumar K, Tripathi BN, Kurade NP, Parihar NS. An Enzyme-linked Immunosorbent Assay using Immonoaffinity-purified Antigen in the Diagnosis of Caprine Paratuberculosis and Its Comparison with Conventional ELISAs. Vet Res Commun 2001;25:539-53.

23- Parolo C, Medina-Sánchez M, de la Escosura-Muñiz A, Merkoçi A. Simple paper architecture modifications lead to enhanced sensitivity in nanoparticle based lateral flow immunoassays. Lab Chip.2013;13:386-90.

24- Maffre P, Brandholt S, Nienhaus K, Shang L, Parak WJ, Nienhaus GU. Effects of surface functionalization on the adsorption of human serum albumin onto nanoparticles - a fluorescence correlation spectroscopy study. Beilstein J Nanotechnol. 2014;5:203647.

25- Sperling $\mathrm{R}$ a, Parak WJ. Surface modification, functionalization and bioconjugation of colloidal inorganic nanoparticles. Philos Trans A Math Phys Eng Sci 2010;368:1333-83.

26- Washburn EW. The dynamics of capillary flow. Phys Rev 1921;17:273-83.

27- Credou J, Berthelot T. Cellulose: from biocompatible to bioactive material. J Mater Chem B. 2014;2:4767.

28- Pelton R. Bioactive paper provides a low-cost platform for diagnostics. TrAC Trends Anal Chem. 2009;28:925-42.

29- Sun J, Guo A, Zhang Z, Guo L, Xie J. A Conjugated Aptamer-Gold Nanoparticle Fluorescent Probe for Highly Sensitive Detection of rHuEPO- $\alpha$. Sensors 2011;11:10490 501.

30- Swets JA. Measuring the Accuracy of Diagnostic Systems. Science. 1988;240:1285-93.

31- Buck AA, Gart JJ. Comparison of a screening test and a reference test in epidemiologic studies. Am J Epidemiol 1968;83:586-92. 